\title{
DEFINITION OF A "SPORT-HEALTH" SEMANTIC SPACE
}

\author{
Millet, Antoine (1,2,3); Abi Akle, Audrey (1); Masson, Dimitri (1); Legardeur, Jérémy (1,2) \\ 1: Univ. Bordeaux, ESTIA, F-64210 Bidart, France; 2: Laboratoire IMS, Université de Bordeaux, \\ Bordeaux, France; 3: SC-Ergomedical, Biarritz, France
}

\begin{abstract}
Product success depends on its capacity to meet users' expectations. Human Centred Design approach helps to reach this success by focussing on users' needs in the design process. These needs are as well functional as hedonic. Designing products requires then to design hedonic properties affecting users' perception. For sport products, people wants to improve their performances while maintaining their health. Sport products are then considered not only "sporty" but also "healthy". Thus, integrating both health and sport expectations into the design process are necessary.

Last decades, Affective Engineering was developed to integrate perception into the design process. Applying this approach for sport products may allow defining and mixing sport and health perceptual characteristics all along the design process. However, defining these characterisitics into requirements implies to translate them into semantic terms. If we observe semantic descriptors for sport products and for health products, they seem opposite. In this paper, we aim defining a semantic space representative and respectful of both domains, sport and health, while they oppose.
\end{abstract}

Keywords: User centred design, Emotional design, New product development

\section{Contact:}

Millet, Antoine

ESTIA

ESTIA-Recherche

France

a.millet@estia.fr 


\section{INTRODUCTION}

Product success depends on its capacity to meet users' expectations. Human Centred Design approach helps to reach this success by focussing on users' needs all over the design process. Jordan (2003) categorized and hierarchized three main levels of needs: functionality, usability and pleasure. The last category, pleasure, takes a significant part of the product experience (Hassenzahl, 2010). Indeed, hedonic properties of products influence users' perception (Norman, 2004). Designing a product requires then to design its affective features to stimulate users' perceptions.

Within the design process, engineers and designers translate users' expectations and therefore perceptual expectations into specifications. To express perception, people communicate with words. Thus, engineers and designers gather and use these words as semantic descriptors to define expected perceptual characteristics like "modern" or "vintage". These descriptors help then designers and engineers to take decision to develop product attributes (shapes, colours or materials). These attributes enhance afterwards products value by arousing users' appropriate affective expectations (Alcantara et al., 2005).

Nowadays, engineers and designers have various methods to relate perceptual characteristics to product attributes. Among them, we observe the Sensorial Evaluation to define a sensorial profile of a product (Osgood, 1952), Semantics to define a semantic profile of a product (Petiot \& Yannou, 2004), the Kansei Engineering to link emotions and affects to product attributes (Nagamashi, 1989), the Emotional Design to convey emotions through the product (Desmet, 2002; Norman, 2004) or more recently the Ux Design to improve user experience (Hassenzahl, 2010; Nicolas, 2011). Despite this diversity, all these methods are considered as Affective Engineering (ENGAGE, 2005; Schütte, 2005; Aziz et al, 2010). According to Jiao, Zhang and Helander (2006), Affective Engineering (AE) can be defined as an approach aiming to incorporate users' affective needs into product physical attributes that deliver users affective satisfaction. In this way, engineers and designers can apply AE to identify and establish relations between perceptual characteristics and physical parts of the product.

Within the context of sport products, users expect with them to improve their performances while maintaining their health (Stefanyshyn \& Wannop, 2015). Designers and engineers need to associate "sporty" and "healthy" requirements within the design process. These associations involve an affective duality. Indeed, for a same functionality, products designed for sport and product design for health do not convey the same affect (see Table 1).

Table 1: Examples of sport and health products

\begin{tabular}{|l|l|}
\hline Sport perceived products & Health perceived products \\
\hline
\end{tabular}

As illustrated in Table 1, sport perceived products seem neat, light and showy. In contrast, health perceived products look rudimentary, solid and dull. Sport and health perceptual properties appear as contradictory i.e. to rest on opposite semantic design spaces. Designers and engineers are then confronted to conciliate these semantic spaces to design a product representative and respectful of both domains, sport and health, while they oppose. Thereby, our research is motivated by a question: Can we define a semantic space representative and respectful of "sport-health" perceptual domain based on these opposite semantic design spaces?

To answer this question, we present in this paper our approach. First, we describe the framework of $\mathrm{AE}$ (section 2.1). Then, we show the process we used to collect semantic descriptors for a "sporthealth" product (section 2.2). Thirdly, we present the experimentation realized, its creation (section 3.1) and its protocol (section 3.2). Finally, we show results of the survey and their analyses (section 4). 


\section{AFFECTIVE ENGINEERING WITHIN THE DESIGN PROCESS}

As defined in (Papalambros, 2015), "design" refers to the result/product as well as the process leading towards design plans. Thus, designing designates the activity following a process. One of the most common of them is the model defined by Pahl \& Beitz (2013). This design process follows four steps. The first one is the task clarification. At this stage, needs are observed, understood and translated into specifications. The second step is the conceptual design. It gathers the ideation phase and the selection of conceptual representations. The third stage is the embodiment design in which the focus is on materialization and the implementation of each part of the system into a functional prototype. The last one is the detail design in which the final prototype is realised.

Engineers and designers use AE to identify and establish relations between perceptual features and physical parts of the product. These relations allow then engineers and designers to better understand perceptual properties of the targeted domain and product characteristics affecting them. For this reason, $\mathrm{AE}$ can be used in the earlier phase of the design process, the task clarification (Jiang et al., 2015; Kwong, Jiang \& Luo, 2016). To obtain this relations, engineers and designers follow the framework of AE defined by Schütte (2005).

\subsection{Affective engineering framework}

The framework of AE as defined by Schütte (2005) is composed of five steps as presented in the Figure1.:

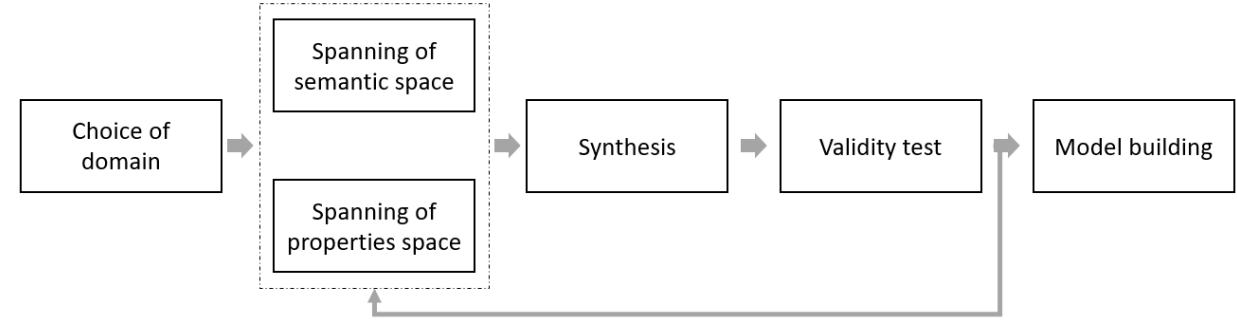

Figure 1: Affective Engineering framework defined by Schütte (2005)

The first step of AE framework is the Choice of domain in which designers, Marketing and engineers focus on selecting the target group, the market and new product specifications. The second step is divided in two parallel tasks in which designers, Marketing and engineers collect information about both users' affective expectations and products from the targeted domain. In the Spanning of semantic space, they collect semantic descriptors of the domain from various media like advertises, users' interviews, experts or more recently from online website using text mining tools (Wang et al., 2018). Depending on designer experience, semantic descriptors are sorted manually or with the help of domain experts or statistically to reduce failure risks from domain experts and designers (Schütte, 2005). A semantic space results from this task. In the Spanning of properties space, engineers, designers and Marketing gather first product representations specific of the selected domain. Then, they decompose products representation into products features (buttons, thickness, materials, colours among others). All collected features form the properties space. Afterwards, during the Synthesis, engineers and designers establish relations between the two spaces defined. It can be realised manually according to the sensibility of experts or designers, statistically with regression analysis or general linear model (Schütte, 2005) or with ranking methods based on fuzzy set theory (Jiang et al., 2015). Within the Validation test and Model building steps, engineers and designers validate the established relations between the two spaces aforementioned. This validation could be performed with experts if non-statistical methods have been used during the Synthesis, or with mathematical model if statistical methods have been used in the previous step of the AE process (see Figure 1). Failures during the Validation involve reconsidering the definition of the spaces.

Definition of the semantic and properties spaces constitutes then the core phase of the AE framework. However, in our context of products with both sporty and healthy images, the definition of the semantic space involves using opposite semantic descriptors. Therefore, we look for sport and health semantic space to observe if several can conciliate both domains to define a "sport-health" semantic space. 


\subsection{Semantics descriptors adapted to "sport-health" products}

In our context of designing products within an AE approach several semantic descriptors are available. As already specified, we are concerned by products with both sporty and healthy representations that seem to be opposed by their semantics. Thus, we search semantic descriptors defining these perceptual domains which may define a sport-health semantic design space.

To realise this task, we focus on scientific publications. We look for studies mentioning "Affective Engineering", "Kansei Engineering" or "Semantics" on online database (Google scholar, Research Gate and Science Direct). Then, we select studies presenting "Sport", "Health" and "Wellness" in their titles, abstract, keywords and review. As result, we obtained a corpus of six studies (see Table 2) composed by three studies focusing on sport products and three studies focussing on health products. We did not noticed studies dealing with AE approach associated to sport and health products at the same time.

Table 2: Corpus of studies used to collect sport and health semantic descriptors

\begin{tabular}{|l|l|l|l|l|l|}
\hline Authors & \multicolumn{1}{|c|}{ Title } & Romain & Date & $\begin{array}{l}\text { Number of } \\
\text { semantic } \\
\text { descriptors } \\
\text { presented }\end{array}$ \\
\hline $\begin{array}{l}\text { Eva, M., } \\
\text { Kim, K., \& } \\
\text { Takatera, M. }\end{array}$ & $\begin{array}{l}\text { Difference between japanese } \\
\text { and french tastes in women's } \\
\text { t-shirts for sportswear }\end{array}$ & $\begin{array}{l}\text { 7th International } \\
\text { Conference on Kansei } \\
\text { Engineering \& Emotion } \\
\text { Research }\end{array}$ & Sport & 2018 & 32 \\
\hline $\begin{array}{l}\text { Green, A., \& } \\
\text { Chattaraman, } \\
\text { V. }\end{array}$ & $\begin{array}{l}\text { Creating an affective design } \\
\text { typology for basketball shoes } \\
\text { using kansei engineering } \\
\text { methods }\end{array}$ & $\begin{array}{l}\text { International Conference } \\
\text { on Applied Human Factors } \\
\text { and Ergonomics }\end{array}$ & Sport & 2018 & 32 \\
\hline $\begin{array}{l}\text { Guo, Y., } \\
\text { Yang, M., \& } \\
\text { Zhou, M }\end{array}$ & $\begin{array}{l}\text { Persuasive semantics of aging } \\
\text { health products based on } \\
\text { AHP and kansei engineering }\end{array}$ & $\begin{array}{l}\text { International Conference } \\
\text { on Applied Human Factors } \\
\text { and Ergonomics }\end{array}$ & Health & 2018 & 16 \\
\hline $\begin{array}{l}\text { Masagué, S. } \\
\text { G., \& Macià, } \\
\text { J. L }\end{array}$ & $\begin{array}{l}\text { User-centered design for } \\
\text { emotion. A case study in } \\
\text { wellness products }\end{array}$ & $\begin{array}{l}\text { Complex Systems Design } \\
\text { \& Management }\end{array}$ & Health & 2014 & 9 \\
\hline $\begin{array}{l}\text { Shieh, M. } \\
\text { D., \& Yeh, } \\
\text { Y. E. }\end{array}$ & $\begin{array}{l}\text { A comparative study on } \\
\text { perceptual evaluations of } \\
\text { sports shoe exterior colors in } \\
\text { Taiwan }\end{array}$ & $\begin{array}{l}\text { Color Research \& } \\
\text { Application }\end{array}$ & Sport & 2014 & 40 \\
\hline $\begin{array}{l}\text { Trujillo, J. L. } \\
\text { H., Aviñó, } \\
\text { A. M. I., \& } \\
\text { Millán, C. L. }\end{array}$ & $\begin{array}{l}\text { User evaluation of } \\
\text { neonatology ward design: an } \\
\text { application of focus group } \\
\text { and semantic differential }\end{array}$ & $\begin{array}{l}\text { Health Environments } \\
\text { Research \& Design Journal }\end{array}$ & Health & 2017 & 25 \\
\hline
\end{tabular}

As presented in the Table 2, each study of this corpus presents between 9 and 40 descriptors that are found in the form of adjectives or expressions. In total, we noticed 154 adjectives or expressions used and selected. After excluding duplications of items, 99 descriptors were remaining. However, we excluded some of them because they were not semantic descriptors like "Too much skin is exposed" or "I like". Thereby, we excluded 13 terms reducing the total number of available semantic descriptors to 86 as listed in the Figure 2 below.

\begin{tabular}{|c|c|c|c|c|c|c|c|c|}
\hline Accessible & Cold & Dull & Feminine & Light & Obtrusive & Rounded & Stable & Trendy \\
\hline Aesthetic & Comfortable & Dynamic & Fitted & Long & Original & Safe & Striking & Uncomfortable \\
\hline Affinity & Common & Ecologic & Formal & Loose & Out of style & Safety & Sturdy & Unrefined \\
\hline Attractive & Complex & Effectiveness & Fragile & Low grade & Professional & Scruffy & Sunny & Vivacious \\
\hline Boldness & Compliant & Elaborate & Functional & Masculine & Provocative & Sharp & Technological & Welcoming \\
\hline Bright & Conventional & Elegant & High grade & Mature & Quality & Short & Thick & Young \\
\hline Casual & Cool & Enjoyment & Homely & Mediocre & Quiet & Showy & Thin & \\
\hline Cheap & Dangerous & Ergonomic & Innovative & Modern & Retro & Simple & Tight & \\
\hline Classic & Delicate & Exclusive & Intimacy & Modest & Rigid & Special & Tough & \\
\hline Clean & Discreet & Expensive & Intuitive & Neat & Rough & Sporty & Traditional & \\
\hline
\end{tabular}

Figure 2: List of semantic descriptors collected from the corpus 
In regard to the application domains of the 6 analysed studies, we noticed 57 semantic descriptors used for sport products, 40 semantic descriptors used for health products and 11 semantic descriptors used for both sport products and health products (in italic into the Figure 2). Based on this observation, it appears some descriptors that may define a "sport-health" product. However, we have to ensure that these 11 semantic descriptors are truly efficient to fully define a "sport-health" semantic space.

\section{EXPERIMENTAL DESIGN}

To observe semantic descriptors defining a "sport-health" semantic space, we designed an online survey. This choice was motivated with the aim of obtaining a large sample of users.

In this survey, we confront each semantic descriptor presented in the Figure 2 to health, sport and "sporthealth" domains. It requires to present each descriptor once per domain. Asking participant to speak about a descriptor is complicate without a context or an immersive situation. To help them, we require pictures specific to sport, health and sport-health domains in our context. Furthermore, to avoid cognitive overload and the influence of a single picture, we cannot use a single image for the evaluation of all 86 descriptors. Therefore, we need to use multiple pictures per domain and to reduce the descriptor amount per picture. We decided to present group of 6 descriptors per picture to stimulate the evaluation.

\subsection{Procedure}

Each descriptor must be evaluated three time, once per domain. Each of them must not be associated with same descriptors while evaluating health, sport and "sport-health" domains to avoid influences of one descriptor on another one. Then, we decompose the list of 86 semantic descriptors presented in section 2.2 into 14 groups of 6 descriptors and one group of 2 per domain (see Figure 3). We give an ID to each descriptor like the code 1 for "Accessible" or 5 for "Boldness". For health domain, we create groups based on given ID as presented below with $n=[1,15]$ :

$$
\begin{aligned}
& \text { Health group } n=\{I D i ; I D i+1 ; I D i+2 ; I D i+3 ; I D i+4 ; I D i+5\} ; \text { if } n=1, i=n ; \text { if } n>1 i=6 * n-5 \\
& \text { Sport group } n=\{I D i ; I D i+5 ; I D i+10 ; I D i+15 ; I D i+20 ; I D i+25\} ; i=6 * n \\
& \text { Sport-health group } n=\{I D i ; I D i+7 ; I D i+14 ; I D i+21 ; I D i+28 ; I D i+29\} ; \text { if } n=1, i=n ; \text { if } n>1 i=6 * n-5
\end{aligned}
$$

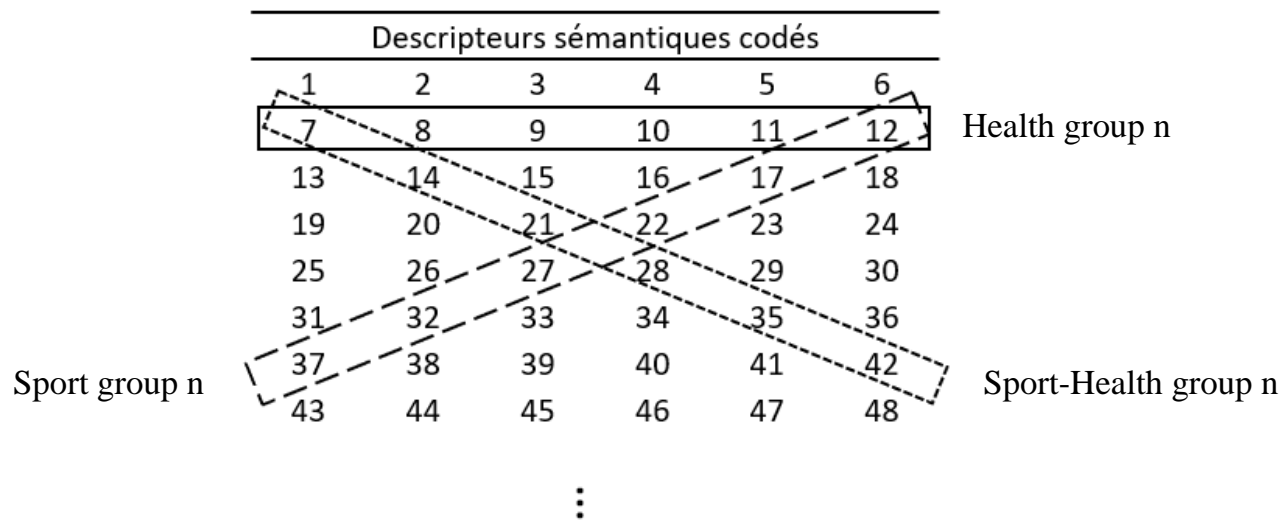

Figure 3: Composition of semantic group confronted to each domain

As mentioned previously, we need multiple image per domain to help participants for the evaluation while avoiding the influence of a single picture. Therefore, we need one picture per group of semantic descriptors for each domain, i.e. 45 pictures in total with 15 representatives of sport, 15 representatives of heath and 15 representatives of sport-heath domains. We give an ID to each picture: $H_{n}$ for health pictures, $\mathrm{S}_{\mathrm{n}}$ for sport pictures and $\mathrm{SH}_{\mathrm{n}}$ for sport-health pictures. Then, we present each picture with one group of semantic descriptors depending on domain: $H_{n}$ with Health group $n, S_{n}$ with Sport group $n$ and $\mathrm{SH}_{\mathrm{j}}$ with sport-health group n. However, to avoid the influence of a picture on descriptor evaluations, we need to change the association between pictures and descriptor groups per participant. Thus, participant $n$ evaluates pictures $n$ with descriptor group $n$ and participant $n+1$ evaluate pictures $\mathrm{n}+1$ with descriptor group $\mathrm{n}$. Furthermore, we decide to evaluate descriptors following a specific sequence to keep participant aroused. They evaluate descriptors first in a health context, then in a sport context and finally in a sport-health context. 


\subsection{Collection of domain representation}

As aforementioned, we need 15 health, 15 sport and 15 sport-health pictures. We collect sport and health pictures from online distributors of sport products and health products. Concerning "sporthealth" pictures, we gather pictures of sport equipment designed for safety like helmet, dorsal protection or shin guard (see figure 4).

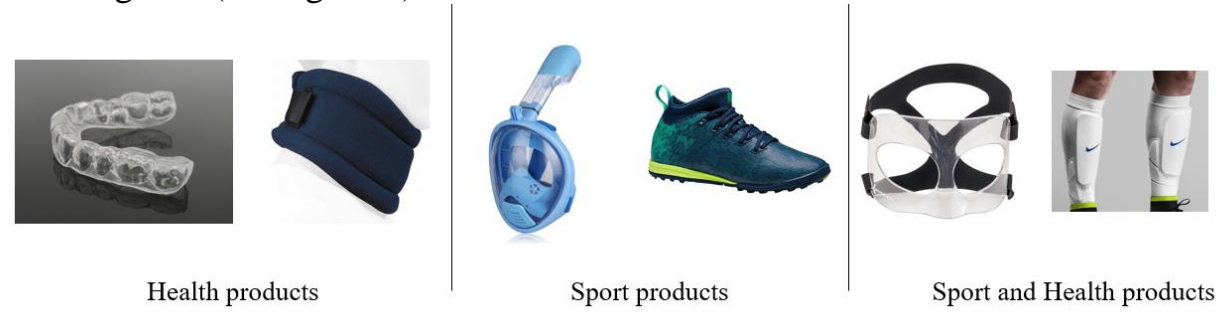

Figure 4: Examples of pictures selected for each domain

\subsection{Structure of the survey}

The survey is composed of three sections: participant profile, descriptor and domain association and suggestions. During the first section, Participant profile, we invite participants to define themselves. We ask then participant to tell their age, gender, mail, physical activity frequency and living place areas. Our context motivates us to ask for physical activity frequency. People practicing sport regularly are experienced with sport products. Due to this experience, they may attach more importance to specific details of the product. Thus, physical activity may influence product perception and therefore the evaluation of semantic descriptors. To categorise participants according to this factor we ask them if they never, occasionally, monthly, weekly or daily practice a physical activity. In a same way, we want to observe if the urban, suburban and rural living areas influence the perception of semantic descriptors too.

In the Descriptor and domain association section, it is asked to participants to establish associations between semantic descriptors and perceptual domains. Statements present an image of one domain and two enclosed questions (see an example in Figure 5). First, participants are invited to associate the product picture with a domain. Then, they associate or not descriptors with the picture. First question allows observing if product perceptions are similar between the designer and the user point of views especially for the "sport-health" products. The second allows identifying links between semantic descriptors and the three domains through domain images. In total, each participant answer to 45 statements during this section of the survey.
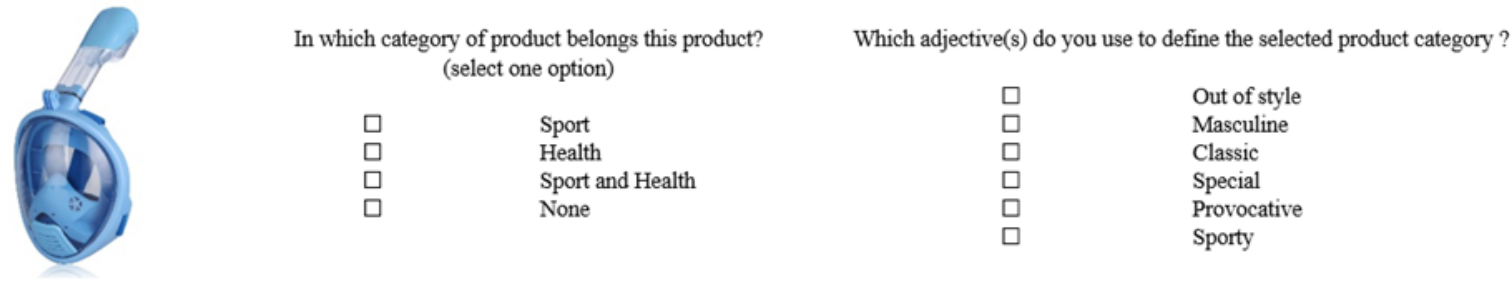

\section{Figure 5: Example of statement presented in the survey}

In section Suggestions, participants are free to suggest semantic descriptors non-mentioned in the survey through open questions for each domain. It allows improving the scope of the survey by implementing new descriptors potentially useful for the definition of a "sport-health" semantic space. The survey is addressed to French participant. All semantic descriptors presented in Figure 2 were then translated in French. Furthermore, the survey was upload online at http://sportsante.herokuapp.com/. This choice was motivated with the aim of obtaining a large sample of participants.

\section{RESULTS}

In total, we collect responses from 39 participants. In the following sections, we present results of the survey based on this participants sample. 


\subsection{Results of the participant profile}

In the participant profile section, we gathered demographic data. First results present a "sporty" population. Participants practicing sport weekly and daily represent respectively $38 \%$ and $31 \%$ of the studied participants sample. Half of them are living in urban area (51\%). Concerning, age and gender, we cannot conclude due to non-communicated responses. Indeed, 33\% of participants did not mentioned their age and 28\% did not mentioned their gender.

\subsection{Domain definition for each image}

First of all, we analyse the association of domain given by participants for each image presented to them in order to ensure that the descriptors linked to an image is well associated to the well domain (as defined by the designers). All domain association means are given in Table 3. We apply the ANOVAbetween statistical test and t-tests post-hoc analysis if necessary (i.e. if ANOVA is significant). We considered the following statistical hypotheses: H0: there is no difference concerning picture perception between the three domains and H1: there is a difference. ANOVA give significant results: $\mathrm{F}(3,56)=42,4 \mathrm{p}<0,000001$ for the health domain, $\mathrm{F}(3,56)=1016 \mathrm{p}<0,000001$ for the sport domain and $\mathrm{F}(3,56)=22,5 \mathrm{p}<0,000001$ for the sport-health domain.

Table 3: Means by picture selected domain for the three domains

\begin{tabular}{|l|l|l|l|}
\hline $\begin{array}{l}\text { Selected domain for } \\
\text { pictures by participant }\end{array}$ & $\begin{array}{l}\text { Association for health } \\
\text { domain (mean) }\end{array}$ & $\begin{array}{l}\text { Association for sport } \\
\text { domain (mean) }\end{array}$ & $\begin{array}{l}\text { Association for sport- } \\
\text { health domain (mean) }\end{array}$ \\
\hline Health & 25,73 & 0,13 & 2,07 \\
Sport & 2,33 & 32,33 & 15,40 \\
Sport-Health & 5,87 & 2,53 & 17,93 \\
None & 4,07 & 3,00 & 2,60 \\
\hline
\end{tabular}

So, we perform a post-hoc analysis (see Table 4). Averages of each variable are described in Figure 5.

Table 4: Results of the t-test

\begin{tabular}{|c|c|c|c|}
\hline Test $\mathrm{T}$ & Health & Sport & Sport-Health \\
\hline Health vs Sport-Health & $\mathrm{t}(28)=6,88 \mathrm{p}<0,0001$ & $\mathrm{t}(28)=6,20$ & $5,65 \mathrm{p}<0,0001$ \\
\hline Heal & $\mathrm{t}(28)=8,83 \mathrm{p}<0$, & $t(28)=5,29$ & $94 \mathrm{p}<$ \\
\hline & $2 p<$ & $5,96 \mathrm{p}<$ & $04 \mathrm{p}<$ \\
\hline & $0,96 \mathrm{p}<$ & $\mathrm{t}(28)=0,71 \quad \mathrm{p}<0$ & $5,25 \mathrm{p}<0$ \\
\hline Sport-Health vs Sport & $\mathrm{t}(28)=1,55 \mathrm{p}<0$, & $\mathrm{t}(28)=37,72 \mathrm{p}<0,0$ & $t(28)=1,01 \quad p<0,3221$ \\
\hline None vs Sport & $\mathrm{t}(28)=1,02 \quad \mathrm{p}<0,3180$ & $\mathrm{t}(28)=33,47 \mathrm{p}<0,0001$ & $t(28)=1,35 \quad p<0,1891$ \\
\hline
\end{tabular}

Results of the t-test indicate that there is a significant difference between the images associated with the Health field and the images associated with the other domains. For sport images as defined by designers, there is a significant difference between images associated with Sport field and images associated with the others. About Sport-health pictures, there is no significant difference between images associated with sport field and images associated with sport-health field.

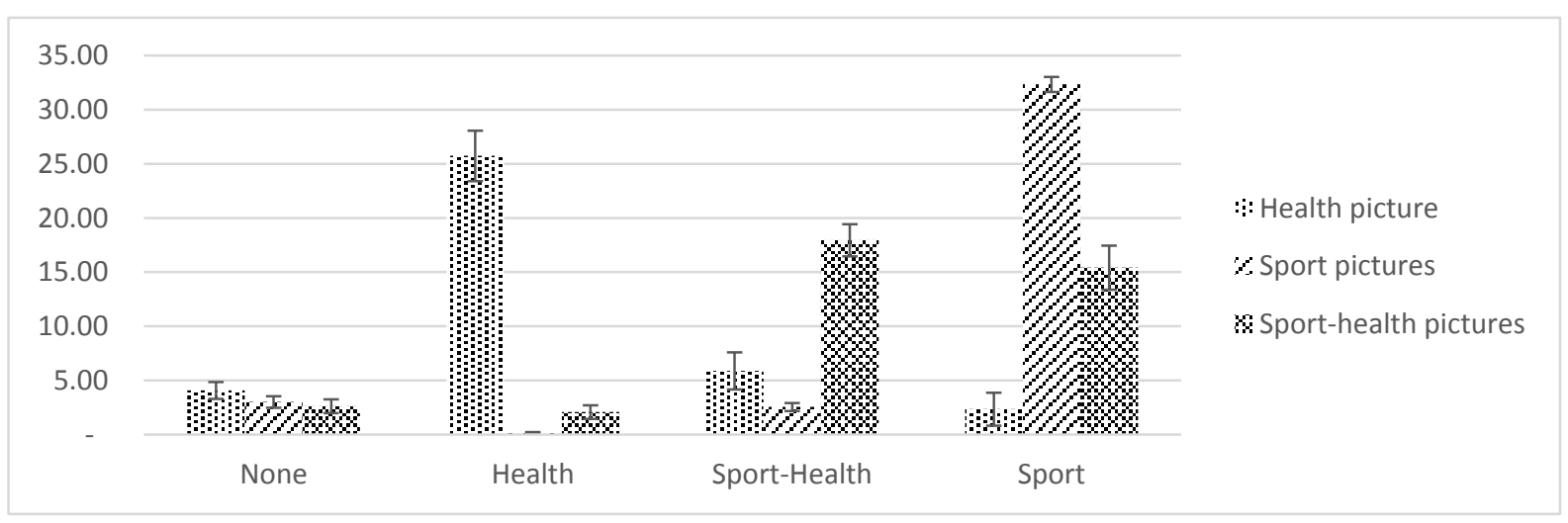

Figure 6: Average and standard deviation for the three picture domains 
These analyses allow us to conclude that sport product pictures are perceived in a same way by both participants and designers. The same applies for sport picture products. However, concerning "sporthealth" pictures, participants perceived them as sport or "sport-health" pictures. Due to this divergence, we focus on both associations with "sport-health" domain pictures as perceived by participants and associations with "sport-health" domain pictures as defined by designers. Therefore, we extract sport-health pictures perceived as such by participants. Extracted pictures were those selected by more than $50 \%$ of participants i.e.: SH5, SH6, SH7, SH9, SH13 and SH14.

\subsection{Descriptors per domain}

We analysed descriptor associations given by participants for each image presented to them. Thus, we relate them with their respective domains of pictures. We compared both associations with sporthealth pictures as defined by designers and associations with sport-health pictures from participants insight (see Table 5).

Table 5: Total, average, median and standard deviation associations of semantic descriptors per domain pictures

\begin{tabular}{|l|c|l|c|c|}
\hline Pictures & $\begin{array}{l}\text { Total of associated } \\
\text { descriptors }\end{array}$ & $\begin{array}{l}\text { Associations } \\
\text { mean }\end{array}$ & $\begin{array}{l}\text { Associations } \\
\text { median }\end{array}$ & $\begin{array}{l}\text { Standard } \\
\text { deviation }\end{array}$ \\
\hline $\begin{array}{l}\text { Sport-Health (designers) } \\
\begin{array}{l}\text { Sport-Health } \\
\text { (participants) }\end{array}\end{array}$ & 77 & 7,8 & 6 & 5,84 \\
\hline
\end{tabular}

We extracted then descriptors with associations superior to medians per sport-health pictures domain according to designers (i.e. 6 associations) and participants insight (i.e. 3 associations). We extract 42 descriptors for sport-health pictures defined by designers and 35 for sport-health pictures as perceived by participants (see table 6 ).

Table 6: Comparison of descriptors associations with sport-health pictures

\begin{tabular}{|lll|lll|}
\hline \multicolumn{3}{|l|}{$\begin{array}{l}\text { Descriptors for Sport-Health pictures as } \\
\text { perceived by }\end{array}$ participants } & & \multicolumn{3}{l|}{ Descriptors for Sport-Health pictures as defined } \\
by designers & & \\
\hline Attractive & Masculine & Technological & Accessible & Intuitive & Safe \\
Casual & Modern & Thick & Affinity & Light & Scruffy \\
Classic & Neat & Tight & Attractive & Long & Sharp \\
Comfortable & Original & Traditional & Bright & Loose & Showy \\
Common & Out of style & Uncomfortable & Classic & Low grade & Sporty \\
Delicate & Professional & Welcoming & Comfortable & Masculine & Stable \\
Enjoyment & Rigid & Young & Common & Modern & Striking \\
Ergonomic & Rough & & Complex & Neat & Sunny \\
Expensive & Sharp & & Delicate & Obtrusive & Technological \\
High grade & Showy & & Ecologic & Original & Thick \\
Intimacy & Sporty & & Enjoyment & Out of style & Tight \\
Intuitive & Stable & & Ergonomic & Professional & Traditional \\
Loose & Striking & & Expensive & Rigid & Uncomfortable \\
Low grade & Sunny & High grade & Rough & Young \\
\hline
\end{tabular}

We notice in Table 6, that descriptors associated with sport-health pictures as defined by designers include 32 descriptors associated with sport-health pictures as perceived by participants (in italic). For the other descriptors, if they appear describing sport-health products with designers' point of view, they may be perceived differently by participants. As mentioned in section 2.2., descriptors were extracted from sport or health semantic spaces. They can then accentuate the sport or health image while conveying a "sport-health" image. 


\section{SYNTHESIS AND CONCLUSION}

In our context, designers and engineers are confronted to design products representative and respectful of both domains, sport and health, while they oppose by their semantics. Therefore, we tried to define a semantic space based on these domains translating a "sport-health" image. We realised this by collecting first 86 semantic descriptors of sport and health domains coming from scientific studies. Then, we developed a survey available online to establish associations between these descriptors and the sport-health domain. As results, we observe that:

- "Sport-health" products are considered as sport products or as sport-health products

- 32 Descriptors from both domains, sport and health, can describe "sport-health" products.

- About sport-health product pictures, 3 additional descriptors (participant) and 8 additional descriptors (designers) may describe the "sport-health" domain.

We can then define a "sport-health" semantic space based on both domain semantic space, sport and health.

\section{DISCUSSION}

In this paper, we tried to define a "sport-health" semantic space within an AE approach based on opposite domain semantics. According to Schütte (2005), semantic descriptors should be extracted from all available sources. We focused on scientific studies dealing with AE. Each of them used semantic descriptors already gathered from various media and suitable for sport and health domains. We based then our analyses on 86 semantic descriptors adapted for sport and health.

As results, we were able observing descriptors representative of a "sport-health" domain based on a population of 39 participants from a survey. The survey is still available online (http://sportsante.herokuapp.com/) to improve the number of responses and carry on the study. Furthermore, interviews associated with storytelling approach will be done with design experts in further studies to refine these results.

The need to translate all semantic descriptors in French may constitute another limit of this study. Indeed, translation from a language to another may create approximations or even modification of the real signification of the semantic descriptors and leads to misunderstandings during the evaluation (Lallemand et al., 2015). The same experimentation can be reproduced in English to observe the influence of language.

Finally, we focused on descriptors representative of "sport-health" domain in this paper. However, each of them was extracted from sport or health fields. These descriptors may then allow designers and engineers manipulating sport and health characteristics of "sport-health" products all over the design process. This perspective will be subject of further researches.

\section{REFERENCES}

Aziz, F.A., Husni, H. and Jamaludin, Z. (2010), “Affective engineering: What is it actually?”, Knowledge Management International Conference, (KMICe2010).

Alcántara, E., Artacho, M.A., González, J.C. and Garcia, A.C. (2005), “Application of product semantics to footwear design. Part I-Identification of footwear semantic space applying differential semantics", International Journal of Industrial Ergonomics, Vol. 35 No. 8, pp. 713-725.

Desmet, P. (2002), Designing emotions, Delft University of Technology, Department of Industrial Design.

Eva, M., Kim, K. and Takatera, M. (2018), “Difference Between Japanese and French Tastes in Women's Tshirts for Sportswear", KEER2018, Go Green with Emotion. 7th International Conference on Kansei Engineering \& Emotion Research 2018, Kuching, Malaysia, 19-22 March 2018, Linköping University Electronic Press, No. 146, pp. 489-494.

Green, A. and Chattaraman, V. (2018), "Creating an Affective Design Typology for Basketball Shoes Using Kansei Engineering Methods", International Conference on Applied Human Factors and Ergonomics, Springer, Cham, pp. 355-361.

Guo, Y., Yang, M. and Zhou, M. (2017), "Persuasive Semantics of Aging Health Products Based on AHP and Kansei Engineering”, International Conference on Applied Human Factors and Ergonomics, Springer, Cham, pp. 337-346.

Hassenzahl, M. (2010), “Experience design: Technology for all the right reasons”, Synthesis lectures on humancentered informatics, Vol. 3 No. 1, pp. 1-95. 
Jiang, H., Kwong, C.K., Liu, Y. and Ip, W.H. (2015), “A methodology of integrating affective design with defining engineering specifications for product design", International Journal of Production Research, Vol. 53 No. 8, pp. 2472-2488.

Jordan, P.W. (2003), Designing pleasurable products: An introduction to the new human factors, CRC press.

Kwong, C.K., Jiang, H. and Luo, X.G. (2016), "AI-based methodology of integrating affective design, engineering, and marketing for defining design specifications of new products", Engineering Applications of Artificial Intelligence, Vol. 47, pp. 49-60.

ENGAGE (2005), European Project on Engineering Emotional Design Report of the State of the Art- Round 1, Report Valencia.

Lallemand, C., Koenig, V., Gronier, G. and Martin, R. (2015), “Création et validation d'une version française du questionnaire AttrakDiff pour l'évaluation de l'expérience utilisateur des systèmes interactifs", Revue Européenne de Psychologie Appliquée/European Review of Applied Psychology, Vol. 65 No. 5, pp. $239-252$.

Masagué, S.G. and Macià, J.L. (2015), "User-Centered Design for Emotion. A Case Study in Wellness Products", Complex Systems Design \& Management, Springer, Cham, pp. 193-206.

Nagamachi, M. (1989), "Kansei engineering approach to automotive”, Journal of the Society of Automotive Engineers of Japan, Vol. 43 No. 1, pp. 94-100.

Nicolas, O., Carlos, J. and Aurisicchio, M. (2011), "The scenario of user experience”, DS 68-7: Proceedings of the 18th International Conference on Engineering Design (ICED 11), Impacting Society through Engineering Design, Vol. 7: Human Behaviour in Design, Lyngby/Copenhagen, Denmark, 15.-19.08. 2011.

Norman, D.A. (2004), Emotional design: Why we love (or hate) everyday things, Basic Civitas Books.

Osgood, C.E. (1952), "The nature and measurement of meaning”, Psychological bulletin, Vol. 49 No. 3, pp. 197.

Pahl, G. and Beitz, W. (2013), Engineering design: a systematic approach, Springer Science \& Business Media.

Papalambros, P.Y. (2015), "Design science: why, what and how”, Design Science, Vol. 1.

Petiot, J.F. and Yannou, B. (2004), "Measuring consumer perceptions for a better comprehension, specification and assessment of product semantics", International Journal of Industrial Ergonomics, Vol. 33 No. 6, pp. $507-525$.

Schütte, S. (2005), Engineering emotional values in product design: Kansei engineering in development, Doctoral dissertation, Institutionen för konstruktions-och produktionsteknik.

Shieh, M.D. and Yeh, Y.E. (2015), "A comparative study on perceptual evaluations of sports shoe exterior colors in Taiwan”, Color Research \& Application, Vol. 40 No. 2, pp. 178-193.

Stefanyshyn, D.J. and Wannop, J.W. (2015), "Biomechanics research and sport equipment development", Sports Engineering, Vol. 18 No. 4, pp. 191-202.

Trujillo, J.L.H., Aviñó, A.M.I. and Millán, C.L. (2017), “User Evaluation of Neonatology Ward Design: An Application of Focus Group and Semantic Differential”, HERD: Health Environments Research \& Design Journal, Vol. 10 No. 2, pp. 23-48.

Wang, W.M., Li, Z., Tian, Z.G., Wang, J.W. and Cheng, M.N. (2018), "Extracting and summarizing affective features and responses from online product descriptions and reviews: A Kansei text mining approach", Engineering Applications of Artificial Intelligence, Vol. 73, pp. 149-162. 